\begin{tabular}{|c|c|c|}
\hline \multirow{3}{*}{$\begin{array}{l}\text { ITC 4/46 } \\
\text { Journal of Information Technology } \\
\text { and Control } \\
\text { Vol. 46 / No. 4 / } 2017 \\
\text { pp. 445-458 } \\
\text { DOI 10.5755/j01.itc.46.4.18470 } \\
\text { @ Kaunas University of Technology }\end{array}$} & \multicolumn{2}{|c|}{$\begin{array}{l}\text { Service-Oriented Architecture Solution } \\
\text { for ECG Signal Processing }\end{array}$} \\
\hline & Received 2017/05/21 & Accepted after revision 2017/10/23 \\
\hline & \multicolumn{2}{|c|}{ Cross } \\
\hline
\end{tabular}

\title{
Service-Oriented Architecture Solution for ECG Signal Processing
}

\section{Tomas Blažauskas, Alvydas Muliuolis}

Faculty of Informatics, Kaunas University of Technology, Studentu str 50, 51368 Kaunas, Lithuania e-mails:tomas.blazauskas@ktu.lt, alvydas.muliuolis@ktu.lt

\section{Liepa Bikulčienè, Eglè Butkevičiūtè}

Faculty of Mathematics and Natural Sciences, Kaunas University of Technology, Studentu str 50, 51368 Kaunas, Lithuania, e-mails: liepa.bikulciene@ktu.lt,egle.butkeviciute@ktu.lt

Corresponding author: tomas.blazauskas@ktu.lt

This paper introduces a distributed service-oriented system, which is developed to provide ECG (electrocardiogram) monitoring, analysis and storage services. The Service-Oriented Architecture system design is introduced for ECG signal transmission and processing. The implementation of cloud-based web-services and overall system architecture is described. The presented system includes a T-shirt with five electrodes intended for the acquisition of the signal. The ECG data for the experiment were recorded while the participant was moving. The signal replicates real conditions and the ECG data contain different high and low frequency noise. Therefore, this paper includes analysis of data filtering methods, model selection and ECG parameter calculation algorithms. The DWT algorithm was selected for the high frequency noise reduction and the BEADS method was used for trend removal. It was experimentally identified that these algorithms are effective and can be used in the system under development. The tests covering overall system were performed on an Amazon cloud computing infrastructure. The results are presented together with a discussion of various constraints of service-oriented performance.

KEYWORDS: Service-Oriented Architecture, high performance computing, ECG analysis, signal processing.

\section{Introduction}

With the increase of healthcare services in non-clinical environments using vital signs provided by wearable sensors, the need to process and analyse the physiological measurements are growing significantly [18]. An integrated solution of different sensors, smart interfaces, modelling, and data analysis technique should warrant that the created system is comfortable and effective for assessing the individuality and dynamics of 
a functional state during the daily-life activities and for the control of the exercise intensity.

To collect the data of the signal, a wearable device with five electrodes inserted into it, was used. Each of them contains different low and high frequency noise. This requires identifying and filtering out irrelevant sensor signals. Services built on top of the data collected by wearable devices need to provide useful information in real time calculations. That requires storage and processing of efficient (near) real-time data.

The extraction of parameters from the ECG signal is important, because the decision-making algorithm incorporates the evaluation of the ECG parameters. Recording the ECG signal at rest is an easy task. However, the records contain various origin noise during physical activity. Since storing the original signals takes too much space on a server [34], the parameter values may also be used as a compression of the ECG signal. This problem becomes important when the amount of the data increases. Future works will include methods to overcome the problem.

\section{Related Works}

Service-Oriented Architecture (SOA) systems for health monitoring are popular in health centres, clinics and smart home environments. These systems are used by elderly people, patients, sportsmen, etc. The most popular framework in a remote health monitoring system contains a three-tier architecture: a Wireless Body Area Network (WBAN), communication and networking system and a service layer. For instance, one of the suggestions was to use a system which contains wearable sensors to measure various physiological parameters, such as blood pressure and body temperature [6]. There are the health monitoring systems, utilizing similar cloud-based medical data storage. One of such systems [33] is used by doctors to access the stored data online using content service application. The electronic remote health monitoring systems sometimes can replace the conventional health care methods. However, integration of the Internet of Things (IoT) paradigm into these systems can further increase intelligence, flexibility and interoperability [31]. A device which utilizes the IoT is uniquely addressed and can be identified anytime and anywhere through the Internet. IoT-based devices in remote health monitoring systems can automatically connect and exchange the information with each other or with health institutes through the Internet. This allows to simplify the set-up and administration tasks significantly. In literature, there are some examples of the systems that can send automatic alarms to the nearest healthcare institute when supervised patient gets into critical accident [7]. In this paper, the proposed training system is also a type of health care system. In production, there is only one similar product, named QardioCore [29]. It evaluates the heart condition using ECG signal analysis and makes training intensity suggestions. Other products only evaluate the heart rate (HR). The heart rate (HR) is widely used to control workloads [15], but it does not reflect many other important physiological processes that ensure safety and effectiveness of physical activity. To personalize user health status, the monitoring system must efficiently process data of the sensors and visualize the holistic view (based on the complex systems theory [34]). Furthermore, the system should give feedback for the user about individualized intensity and duration of the training. The complexity of a signal (in a particular case, some characteristics of electrocardiogram (ECG) signal) may reflect human functional state and healthiness.

A variety of methods for the automated ECG analysis have been developed in the past few decades to simplify the monitoring task. The adaptive filtering [28], singular value decomposition (SVD) [12], independent component analysis (ICA) [37], neural networks [4], wavelet transform [14] are the most popular ones. However, almost all of these methods are not suitable for wearable sensors and real-time ECG filtering. Adaptive filtering and SVD methods are simple and fast in operations. Nevertheless, these methods fail if the data contain too much high and low frequency noise while the participant is moving. Wavelet transform and ICA methods are effective in eliminating the common ECG noises. However, both methods have high computational complexity, which is rather challenging to achieve in real-time ECG filtering. The methods with Neural Network algorithms require a lot of time for the ECG noise training and are not appropriate enough for individualized ECG filtering. In this paper, a Discrete Wavelet Transform (DWT) [8] method was selected for the high frequency noise reduction and the BEADS algorithm [26] for the trend removal. 


\section{Service-Oriented Architecture for ECG Monitoring}

In this paper, the implementation of the minimal ECG monitoring system, which includes cloud-based ECG processing, was selected. It consists of the following functional units:

- A cardiograph device with its sensors, enabled to capture human state and provide information to a logging device located nearby;

_ A logging device which collects information from the sensors and transmits it to a remote computer (server);

_ A remote computer which receives, stores, analyses the data and provides feedback.

The implementation of these functional units and their relations are presented in Fig. 1. The arrows show the component usage relation.

Figure 1

Service-Oriented Architecture system components

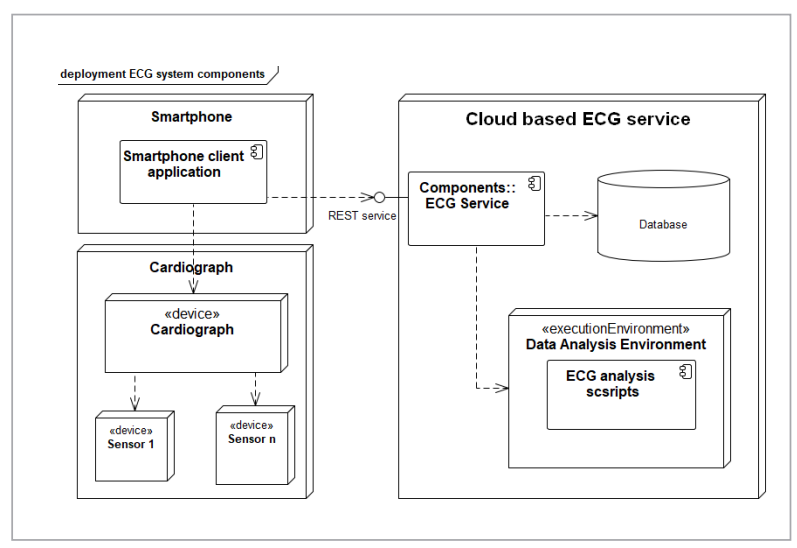

The cardiograph node includes the cardiograph device and cardiograph sensors. The cardiograph acquires cardio signals using its sensors, converts them into digital data and transmits them to smartphone application using Bluetooth connection.

The logging device can be specially designed hardware and software or some general-purpose device which supports communication means required by cardiograph and remote computer. For this research, a smartphone has been chosen. Besides acting as a communication bridge between cardiograph and remote computer, the smartphone serves as the tool to provide feedback.

\subsection{Services for ECG Monitoring System}

The components of cloud-based services are described in this section, and it is the main part of the whole ECG system providing web services to store, analyse data and

provide the results, influencing all the other components. Cloud services consist of several software components, which can be used as distributed resources to provide the scalability of the system.

\subsection{Server-Side Software Architecture}

The simulation of complex cyber-physical systems is often regarded as expensive [38] in terms of the computational power. Therefore, the system which, on one side, is flexible and does not require exceptional computer power to handle service requests and, on the other side, may be implemented using distributed computer resources or other calculation capability (e.g. supercomputer for parallel calculations), was designed.

A system deployment scheme is provided in Fig. 2.

\section{Figure 2}

A web service system deployment scheme

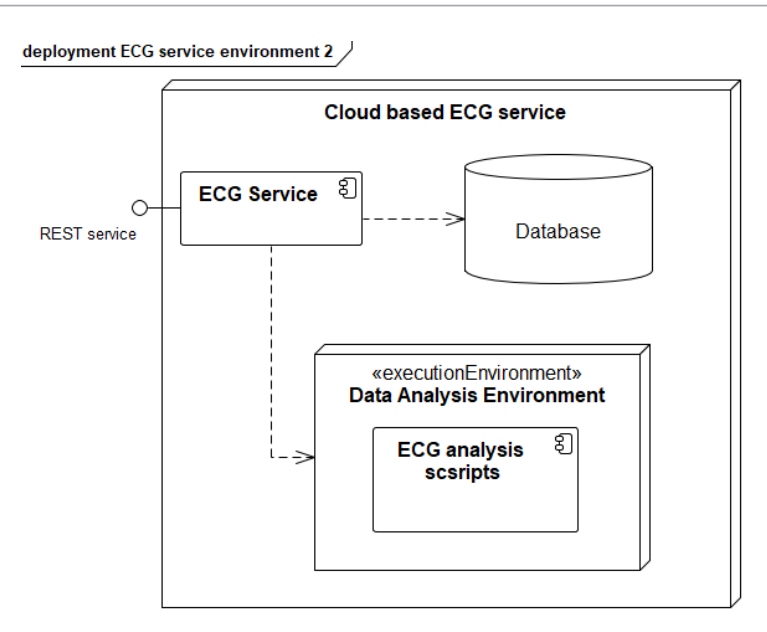

The system uses two different software components to provide services for the following client software:

- ECG Service. This software is communicating with the client's software to provide actual services, based on the Representational State Transfer (REST) implementation. It is used to provide services, but does not perform data analysis operations itself. The main functionalities of the service are to receive ECG data, call Data Analysis 
Environment algorithms and provide the results of the ECG data analysis to the client's software.

- Data Analysis Environment. The software performs the analysis of the ECG data provided.

The system can run many parallel data analysis environment instances and control them. Therefore, the system is scalable, i.e. the overall performance of the system can be improved by assigning more computation resources.

Scalability is very important for the system, because it gives the possibility to control the load and effectively use the cloud computing resources. For example, more computing power can be acquired for the short periods of time, when the system is handling an increased number of simulation requests. Particularly, using the cloud computing, dynamic scalability becomes more attractive and practical because of the unlimited resource pool [16].

\subsection{Data Analysis Environment}

Data Analysis Environment (see Fig. 3) in the presented ECG monitoring system concept refers to a subsystem, consisting of MATLAB software and scripts, designed for the ECG parameter calculation.

All the scripts are included in the package named Analysis Scripts. This package uses MATLAB libraries as well as some custom libraries, helping to implement BEADS algorithm. The Analysis scripts package includes the following functionalities: Low Frequency Filter, High Frequency Filter, and Parameter Acquisition.

\section{Figure 3}

A general overview of the Data Analysis Environment

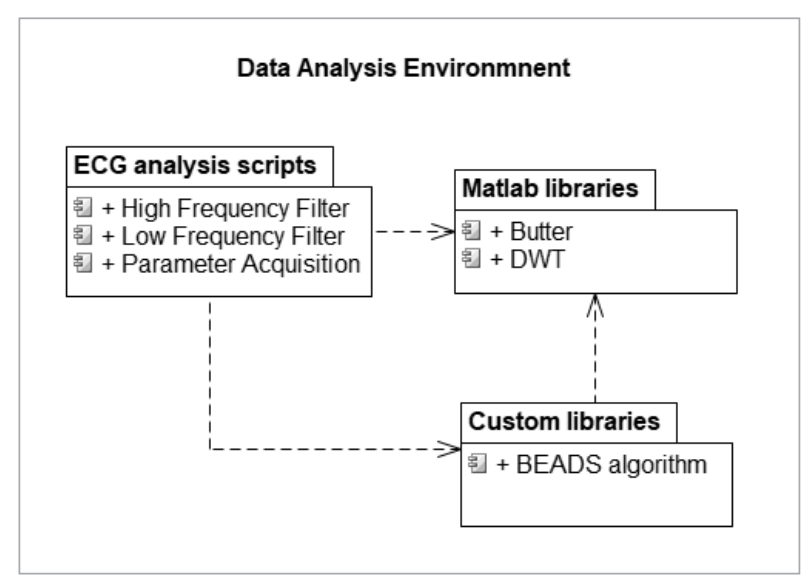

\section{The ECG Processing Algorithms}

The electrocardiogram (ECG) is a non-invasive measure of the cardiac electrical activity recorded by electrodes attached to the skin. Each heartbeat is an electrical impulse ("wave") traveling through the heart [3]. Usually, ECG signals are taken in stationary condition and the transmission of ECG often introduces noise due to poor channel conditions [3]. Despite signal variability, the signal noise comes from many sources, such as power line interfaces, muscular artefacts, electrode contact noise, baseline wanderings due to respiration, instrumentation noise generated by electronic devices, etc. [13], [19]. The ECG signal for medical and diagnostic purposes must be free from undesired disturbances and noise. Our task is to analyse these signals when the person is moving and doing exercise. The electrodes are embedded into T-shirts in order to reduce the noise by direct contact with the body surface. The ECG signal should be sampled with frequency of below $500 \mathrm{~Hz}$, otherwise, it is not suitable for implementation in portable device (mobile) systems due to high computational demands [19].

There are three main problems in the initial ECG signal data analysis:

_ Data trend removal. The trend in the ECG signal is understandable as low frequency noise (baseline). The trend appears as the result of muscle movement during an ECG recording.

- Noise reduction. In this case, it is understandable as a high frequency filter. High frequency noise is the result of electric uncertainty recording to ECG signal.

- Parameters calculation and data compression for the storage.

\subsection{Data Filtering}

The trend of the ECG signals is low when the person is not moving, and it could be removed by using low-order polynomial methods [2] or data could be subtracted from each time-series signal object. In this paper, the trend is considered as a low-frequency noise, which is not stationary or linear. It is assumed that noisy ECG data $y(n)$ can be modeled as:

$$
y(n)=f(n)+x(n)+w(n), n=0, \ldots, N-1,
$$


where $f$ is a low-pass signal, $x$ is a sparse-derivative signal, and $w$ is a stationary white Gaussian noise [36]. For the data like $y(n)$, it is not suitable to use neither low-pass filtering, nor sparsity-based denoising methods. However, a combination of these two methods is found to be suitable [35].

The high-pass digital filter can be characterized by its transfer function which has the form:

$$
H=H(z)=\frac{B(z)}{A(z)}=\frac{b_{0}+b_{1} z^{-1}+b_{2} z^{-2}+\cdots+b_{N} z^{-N}}{1+a_{1} z^{-1}+a_{2} z^{-2}+\cdots+a_{N} z^{-N}},
$$

where the order of the filters is greater than $N$, [22]. The low pass filter $L$ can now be defined as:

$$
L=I-H,
$$

where $I$ is the identity matrix. The combined methods of conventional low-pass filtering and sparsity-based denoising are usually complex and require long lasting calculations. The Baseline Estimation and Denoising with Sparsity (BEADS) [26] algorithm is used for trend removal of the ECG signals in the system. The BEADS trend removal algorithm is based on data baseline (or low-frequency noise wave) detection and its removal.

This algorithm requires some definitions. The filters $L$ and $H$ were taken with zero-phase, non-causal and recursive. There are two specification parameters of the filter: its order $2 d$ and its cutoff frequency $f_{c}$ [35], [26]. Moreover, by using the commutative property of Linear, Time-Invariant (LTI) systems, the filter $H$ is defined as

$$
H=B A^{-1},
$$

where $A$ and $B$ are the finite matrices and they are not exactly commutative [35], [26]. Furthermore, if $x=v$, the cost function can be defined as:

$$
\begin{aligned}
& G(x, v)=\frac{1}{2}\|H(y-x)\|_{2}^{2}+x^{T}[\Gamma(x, r)]+ \\
& +\sum_{i=0}^{M}\left[\frac{\lambda_{i}}{2}\left(D_{i} x\right)^{T}\left[\Lambda\left(D_{i} v\right)\right]\left(D_{i} x\right)\right]+c(v),
\end{aligned}
$$

where $c(v)$ is a scalar that does not depend on $x$ and $\lambda_{i} \geq 0$ are regulation parameters, $D_{i}$ is the order- $i$ difference operator, $\Gamma(x, r)$ is a diagonal matrix that depends on asymmetric parameter $r$ [8]. Furthermore,
$\left[\Lambda\left(D_{i} v\right)\right]_{n, n}=\frac{\varphi^{\prime}\left(v_{n}\right)}{v_{n}}$

depends on penalty function $\varphi$. For example, if $\varphi(x)=$ $|x|$, then $\left[\Lambda\left(D_{i} v\right)\right]=\frac{1}{D_{i} v} \operatorname{sign}\left(D_{i} v\right)$ [35], [26].

The cost function $G(x, v)$ is needed in order to find the data baseline. Minimizing $G(x, v)$ with respect to the following solution:

$$
\begin{aligned}
x & =\left(H^{T} H+\sum_{i=0}^{M} \lambda_{i} D_{i}^{T}\left[\Lambda\left(D_{i} v\right)\right] D_{i}\right)^{-1} H^{T} H y= \\
& =A Q^{-1} B^{T} B A^{-1} y
\end{aligned}
$$

where $Q=B^{T} B+A^{T}\left(\sum_{i=0}^{M} \lambda_{i} D_{i}^{T}\left[\Lambda\left(D_{i} v\right)\right] D_{i}\right) A$.

The T-shirts have five electrodes that are inserted into different places and three ECG leads are recorded from these electrodes. All recorded signals from the ECG registration device are sent as a data set to the smart phone. There are many different exercises that participant might perform, so the trend might also vary.

ECG simulator data were used for calculation verification to check if BEADS algorithm works fine. Each value of the signal is taken every $2 \mathrm{~ms}$ at 500 $\mathrm{Hz}$ frequency. The simulator generates $150 \mathrm{bpm}$ sinusoids (pure ECG signal). The low and high frequency noise was added to the simulated electrocardiogram. The BEADS algorithm was compared with other algorithms (Butterworth filter [17], Fast Fourier Transform algorithm (FFT) [10] and Finite Impulse Response filter (FIR) [21]). In addition, random Gaussian values with scalar 10 (which means the signal-to-noise ratio per sample, $\mathrm{dB}$ ) were enclosed as a high frequency noise and the sinusoid:

$$
f(t)=0.3 \cdot \sin (0.9 \cdot \pi \cdot t)+0.001 \cdot \text { rand }
$$

as a low frequency noise (trend). Here rand is random scalar values with standard normal distribution. The simulated ECG signal is presented in Fig. 4.

The BEADS algorithm has the asymmetry parameter which could vary. During analysis, it was noticed that the best value is from 1 to 6 due to low Root Mean Square Error (RMSE) values.

Furthermore, the 9-th order Butterworth filter [17] was selected for error comparison. The normalized 
frequency may vary from 0 to 1 . However, the values from 0 to 0.5 for low-pass filtering are taken. The RMSE was taken as a measurement to find the best frequency in the BEADS and Butterworth methods.

Figure 4

Simulated ECG signal

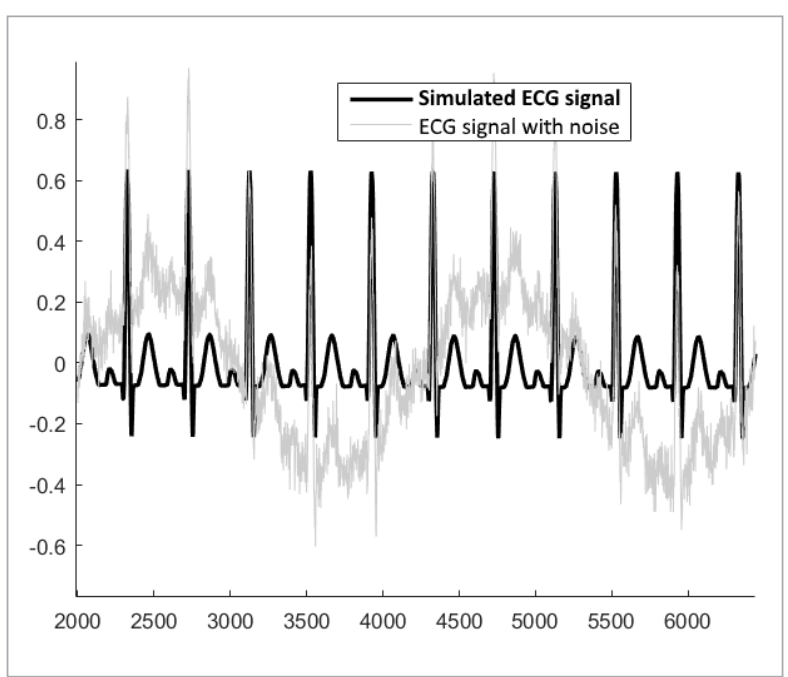

The results are presented in Table 1 . The best frequency from the table is $f_{c}=0.01$. The Butterworth filter causes small RMSE values. However, the BEADS algorithm is more accurate (Table 1 ).

Table 1

A comparison of BEADS and Butterworth

\begin{tabular}{c|c|c}
\hline \multicolumn{1}{c|}{$\boldsymbol{c} \boldsymbol{c}$} & RMSEBEADS & RMSEButterworth \\
\hline 0.01 & 0.1 & 0.15 \\
\hline 0.02 & 0.12 & 0.13 \\
\hline 0.04 & 0.14 & 0.14 \\
\hline 0.05 & 0.14 & 0.15 \\
\hline 0.07 & 0.15 & 0.16 \\
\hline 0.08 & 0.15 & 0.16 \\
\hline 0.1 & 0.15 & 0.16 \\
\hline 0.11 & 0.15 & 0.17 \\
\hline 0.13 & 0.16 & 0.17 \\
\hline$\ldots$ & $\ldots$ & $\ldots$ \\
\hline 0.5 & 0.16 & 0.17 \\
\hline
\end{tabular}

\section{Figure 5}

The trend removal from the ECG signal using the BEADS algorithm: a) original signal; b) baseline (black) and original signal (grey); c) signal after the BEADS algorithm; d) residuals

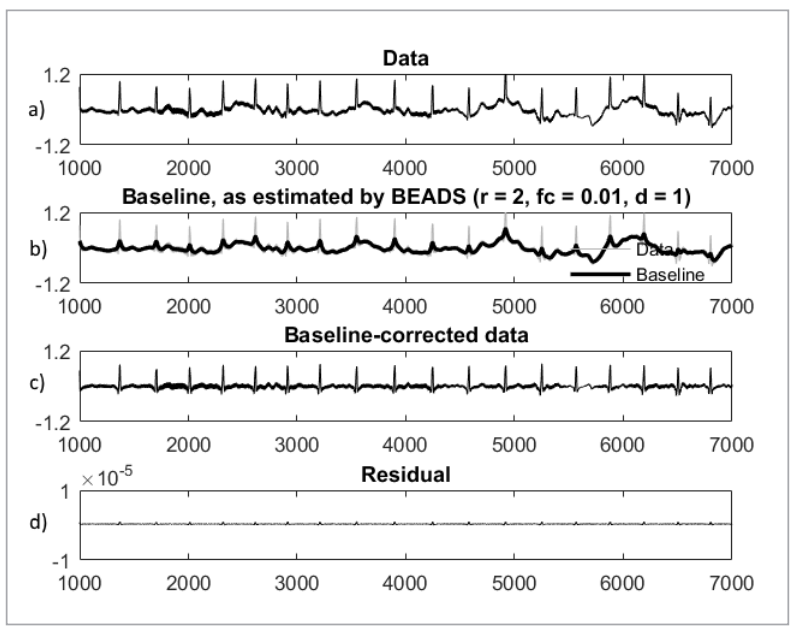

Fig. 5 shows how the BEADS algorithm works when a person with a special T-shirt is walking. The asymmetry ratio $r=2$, filter order $d=1$, and filter cut-off frequency $f_{c}=0.01$ are the values in this example.

The BEADS algorithm works fine and the residuals (original data minus baseline minus baseline-corrected data) are low (see Fig. 5). However, the complexity is also important because the real-time results are necessary during the exercises.

Figure 6

Complexity of BEADS algorithm

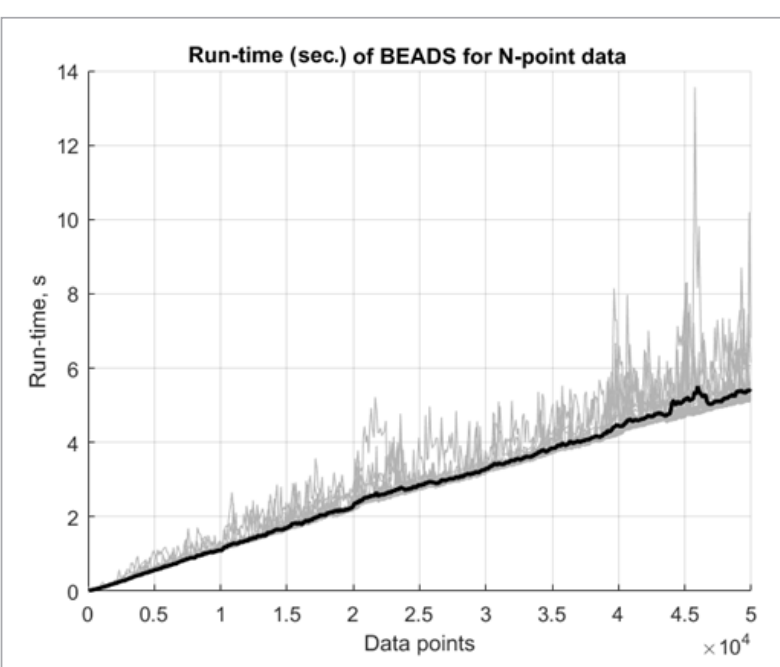


The run-time of BEADS for $\mathrm{N}$-point data is presented in Fig. 6. Sometimes the run time may reach as much as $30 \mathrm{~s}$. The reason behind this variability is that BEADS calculates coefficients of the high-pass filter, while cost function (1.5) does not reach the desired low value. The inverse matrices (see (1.7)) are found during these calculations. In some cases, it is complex to calculate the inverse matrices and it requires more time. This causes the peaks, which can be seen in Fig. 6. The run-time average of 50 iterations (thicker line) shows that the complexity of the BEADS algorithm is linear.

The BEADS algorithm was used to reduce the low frequency noise (trend removal). The ECG signal also has a high frequency noise (as it was mentioned before) which was not reduced by the BEADS algorithm.

Fast Fourier Transform (FFT) is one of the most popular methods to reduce high frequency noise. However, this technique fails to provide the information about exact location of frequency components in time [10]. The Discrete Wavelet Transform (DWT) algorithm was chosen for ECG signal analysis. The DWT algorithm is appropriate to be used for non-stationary signals (like ECG) because it decomposes the signal into a frequency time scale [13]. This method is based on wavelet transformation, in which copies of the main pattern ("mother wavelet") are scaled and shifted [13]. Each analysing wavelet has its own time duration and time location [10]. The mother wavelet in DWT is discretized and can be written as follows:

$$
\psi_{a, b}(x)=\frac{1}{\sqrt{a}} \psi\left(\frac{t-b}{a}\right),
$$

where $b$ is a translation parameter of prototype wavelet $\psi(t)$, and $a$ is a scale parameter, obtained by means of dilation [14], [13].

The optimal wavelet function must be selected in order to achieve the best noise free signal. Furthermore, the best threshold selection rule and decomposition level should be found. The DWT algorithm has the following three steps [8], [5]:

_ The DWT is applied on a noisy signal.

- The thresholding process is applied. The wavelet coefficients are filtered by throwing them away (resetting to zero) during this process. The idea of this thresholding process is based on an assumption that the noise is generated by small-value wavelet coefficients, while the large coefficients compose the actual signal.

- The remaining coefficients are back-converted in time domain (Inverse Discrete Wavelet Transform (IDWT)).

The DWT algorithm contains many arithmetic operations and requires a large memory storage. This is not desirable for real-time calculations. It is not practical to directly compute the DWT for the entire signal. That is why the three-level wavelet de-noising process [8] was used.

The same simulated data (see Fig. 4) were taken for the comparison of high-pass filters and parameter analysis. However, in this case, the data have no trend. It was removed in the previous step with the BEADS algorithm.

The right wavelet should be selected to find the best solution with the DWT algorithm. The Daubechies wavelets, based on the work of Ingrid Daubechies, are a family of orthogonal wavelets defining a discrete wavelet transform, [13]. Each wavelet type of this class has a scaling function generating an orthogonal multiresolution analysis. Each Daubechies wavelet generates different filtering coefficients.

The higher order leads to better errors but it requires long lasting calculations. If more calculations are required, the model might become insufficient for real time analysis. In this paper, 3400 data points were analysed to find the best wavelet. The RMSE was used to measure the accuracy of DWT with different wavelets (Table 2). The timing is important for real-time data analysis. For this purpose, the calculation time is presented in Table 2.

The DWT algorithm gives the optimal results with wavelets "db11" and "db12": the RMSE values are similar with errors of higher order Daubechies coefficients. Further calculations reduce RMSE slightly. In addition, Daubechies wavelet with the higher order causes minor changes in duration time. However, as was mentioned before, the higher order of these coefficients makes the model more complex and that is undesirable for the real-time calculations. The "db11" will be used for the calculations below. 


\section{Table 2}

The errors of the DWT algorithm and calculation time for different Daubechies wavelets

\begin{tabular}{|c|c|c|}
\hline Daubechies & RMSE & Duration, $\mathbf{s}$ \\
\hline${ }^{\prime} \mathrm{db} 5 ’$ & 0.0579 & 0.4900 \\
\hline 'db6' & 0.0574 & 0.6110 \\
\hline 'db'y' & 0.0570 & 0.8690 \\
\hline 'db8' & 0.0568 & 0.9680 \\
\hline 'db9’ & 0.0564 & 0.7060 \\
\hline 'db10’ & 0.0562 & 0.7760 \\
\hline 'db11' & 0.0559 & 0.8279 \\
\hline 'db12' & 0.0561 & 0.6070 \\
\hline 'db13' & 0.0558 & 1.0760 \\
\hline 'db14' & 0.0561 & 1.7529 \\
\hline 'db15’ & 0.0558 & 0.7558 \\
\hline 'db16’ & 0.0557 & 1.1080 \\
\hline 'db17' & 0.0555 & 0.5440 \\
\hline 'db18' & 0.0555 & 0.7219 \\
\hline 'db19' & 0.0555 & 0.8588 \\
\hline 'db20' & 0.0555 & 0.6396 \\
\hline 'db21’ & 0.0555 & 0.6336 \\
\hline 'db22' & 0.0555 & 0.7249 \\
\hline
\end{tabular}

The DWT algorithm was compared with Butterworth to see which algorithm is more efficient. The DWT algorithm and Butterworth filter give different results. To compare which one was better, the RMSE values were calculated:

$R M S E_{\text {Butterworth }}=0.1206$,

$R M S E_{D W T}=0.0559$.

RMSE shows that the DWT algorithm reduces the noise better (with lower errors).

A DWT filtering example with real data (from Cardioscout multi ECG registering device) is shown in Fig. 7. The first graph shows the ECG data when the participant is walking (the trend is already removed), while the second part of this figure shows denoised data with DWT.
Figure 7

Detrended ECG signal and filtered with DWT

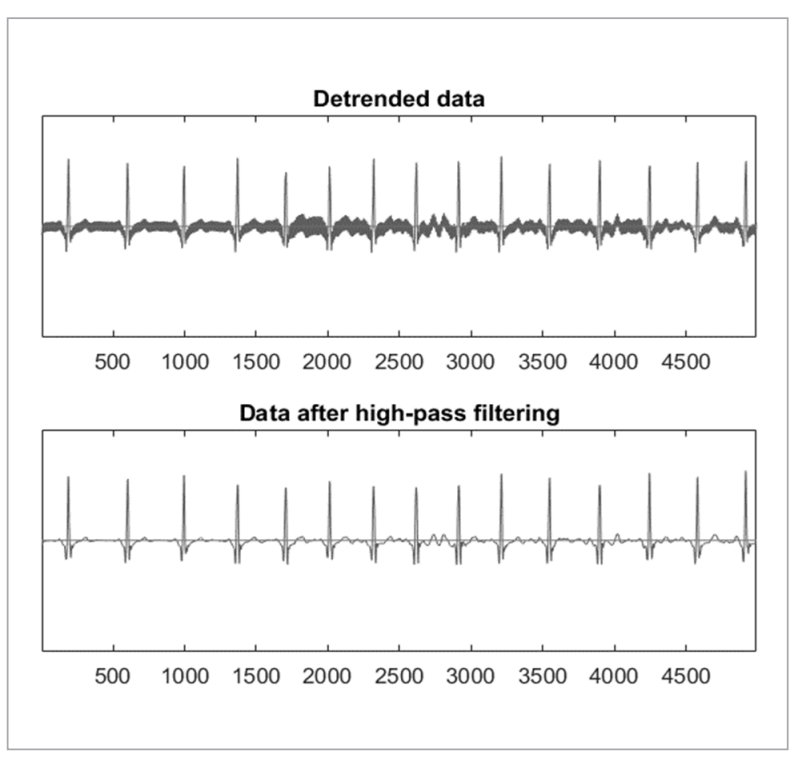

\subsection{ECG Parameters Calculation}

Automatic $\mathrm{R}$-wave recognition is the first processing task of the ECG signal. Later, the QRS complex and other ECG parameters can be measured. The QRS complex (see Fig. 8) includes recognition of their position in time and time interval between them [23]. The QRS complex has the best ratio of signal/noise characteristics. The main detection algorithms of the QRS complex are based on the first or both first and second order derivative calculation for signal and digital filtering. Most of the time local extreme signal detection logic has additional rules that can be applied to reduce the number of false crawls. Wavelet transform [20], filter banks [1], neural networks, adaptive filters, Hidden Markov Models (HMM), mathematical morphology operators, genetic algorithms, Hilbert, length and energy transformations, syntactic methods, MODB algorithms (based on several signal values of derivative product) [23] can also be used for QRS detection. Most of these methods require substantial computing resources, have a big delay, are sensitive to noise and sudden signal change [9], so the commonly used algorithm remains the Pan-Tomkinson algorithm [27] based on the calculation of derivatives.

As was mentioned before, the ECG is used to measure the heart rate and regularity of heartbeats. It shows 
Figure 8

ECG parameters

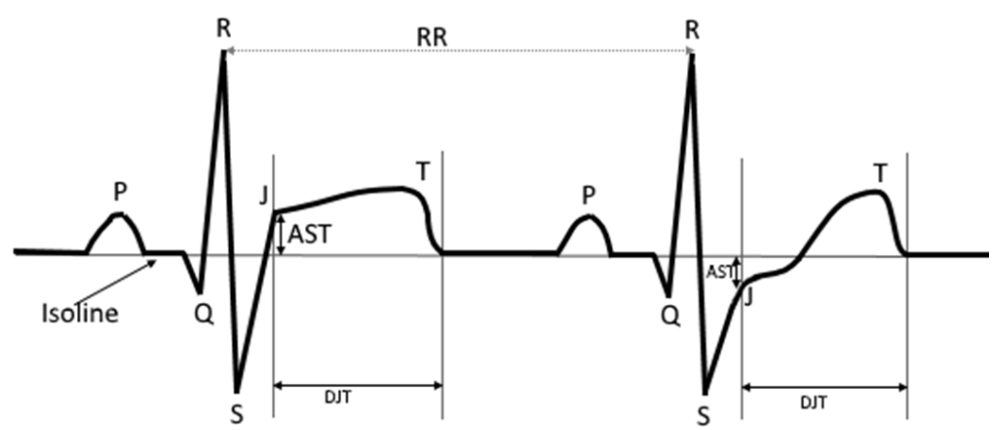

the size and position of chambers. Heart diseases or damages could also be detected [3] from ECG. The ECG signal has a distinct and characteristic shape which is given in Fig. 8.

The purpose of this part of the ECG processing is to find $\mathrm{P}$ and $\mathrm{T}$ waves, QRS complex, AST and DJT parameters (see Fig. 8). Their calculation is based on local extrema and twist points search in RR interval. These parameters will be used in future works to design the decision-making algorithm. The following parameters were chosen by recommendations of sport's medicine specialists:

- The P wave appears because of the contraction in the left and right atria. This wave may be even absent from some ECG recordings [24]. The normal shape of a $\mathrm{P}$ wave does not include any peaks. Furthermore, it can be positive, negative or biphasic [25].

- The QRS complex duration is necessary for the many medical instruments. This complex is made by the contraction of the left and right ventricles. $\mathrm{Q}, \mathrm{R}$, and $\mathrm{S}$ waves involve more muscle mass and are stronger than the $\mathrm{P}$ waves. That is why they have larger fluctuation in the graph [10], [30].

_ The $\mathrm{T}$ wave is necessary for a variety of diagnostic tasks (acute coronary syndrome, acute myocardial infarction, and potentially fatal arrhythmias). This wave is caused by the repolarization of the ventricles [10], [11].

- The JT duration (DJT) reflects the metabolism of the heart. However, when the QRS duration is increased (which contributes to QT prolongation), it has been proposed that the JT interval duration is a more appropriate measure of ventricular repolarization than the QT duration.

_ The ST segment represents the interval between ventricular depolarization and repolarization. This segment in the first stage is the flat, isoelectric section of the ECG between the end of $\mathrm{S}$ wave (the $\mathrm{J}$ point) and the beginning of the $\mathrm{T}$ wave. Myocardial ischaemia, or infarction, is the most important cause of the ST segment abnormality (elevation or depression). This parameter is noted as AST in Fig. 8 [10].

All calculations during the parameter search in Fig. 9 were executed with detrended and high-pass filtered data. In some cases, it is difficult to find the parameters because small parts of the data may still contain noise. These values are taken as average from three previous parameter values.

The effective ECG signal compression demand is quite high, assuming the fact that every year millions of electrocardiograms are recorded and remote transmission that uses the network grows. Effective data compression is needed in many practical applications: ECG data storage, ambulatory monitoring systems, ECG data transmission network. The data compression techniques are divided into those containing compressed data with reconstructed into the original signal and the methods with higher compression ratio achieved by allowing certain errors in reconstructing the signal [32]. The efficiency of the ECG signal 
Figure 9

ECG waves (QRS complex, P and T waves, J wave)

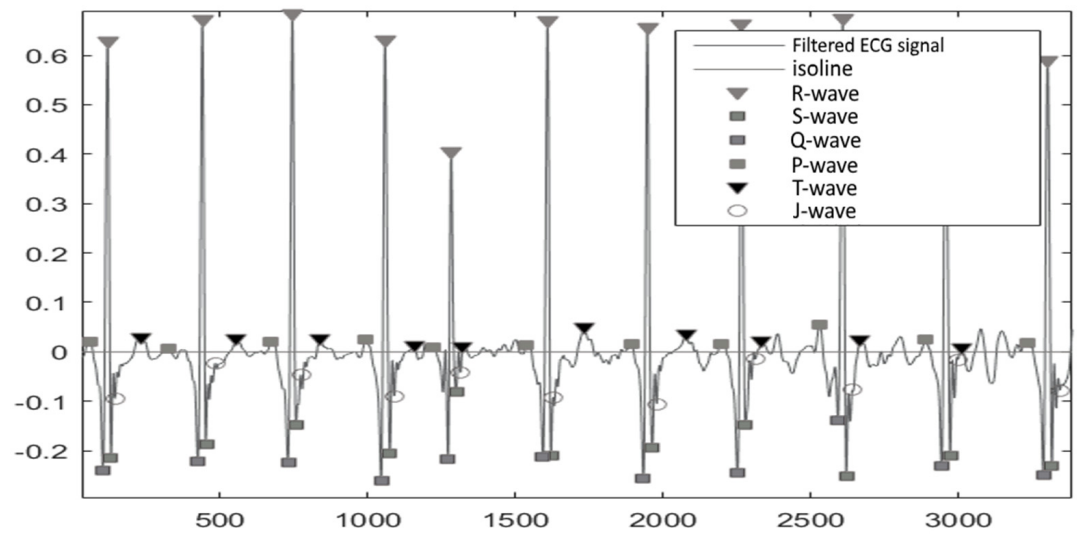

compression can be measured by the ratio between the compressed data and primary data (compression ratio $\mathrm{CR}$ ), primary and compressed data size, time to compress and restore data and error, often referred to as a percentage of the average square difference (percent mean-square difference - PRD).

\section{Performance of the Cloud-Based Solution}

The calculation of the ECG parameters is a resource intensive task. It is necessary to evaluate the performance of the solution to see if it can be applied practically. Two experiments were performed to see how the system handles the load.

The Amazon cloud computing services were used with preconfigured four machines in the experiments. Each machine contained one virtual CPU (Intel Xeon CPU E5-2676 v3, single core, $2.40 \mathrm{GHz}$ ), and 1GB memory. The load balancing mechanism is provided by the Amazon services. The Apache JMeter tool was used for the experiments.

The JMeter tool was set up to create thread group with ramp-up period equal to $10 \mathrm{~s}$ and duration set to $180 \mathrm{~s}$.

The number of threads (users) was increased from 10 to 400 with step 10. Each request was sending 42.5 kilobytes. Requests were delayed with constant timer, which was set to $10000 \mathrm{~ms}$. The average response time was calculated from interval [60s; 120s]. This interval was chosen, because the system must have become stable before calculating average response time. A straight forward approach was used in the first experiment - the requests were generated continuously, increasing the amount of the requests per second, until the system starts degrading. The results are pro-

\section{Figure 10}

Performance of the solution for continuously generated requests

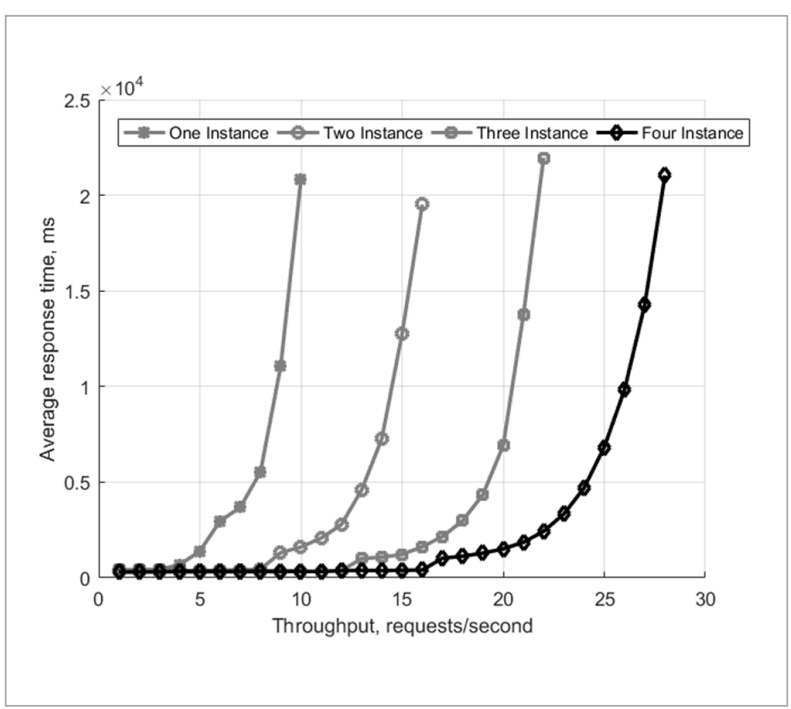


vided in Fig. 10. It shows that the solution, distributed on 4 machines (with given hardware specifications) can handle up to 16 requests per second. The system degrades with bigger load and becomes unusable. To determine how many users are needed to produce the desired requests per second (RPS), the following formula can be used:

Users $=R P S \cdot \frac{\text { Average Response Time }}{1000}$

This metric allows to see how the system performs on stress loads; it does not show how many users our system can handle when implementing our use case. In our use case, each user sends a request every 10 seconds. Therefore, this behaviour was simulated using the Apache JMeter tool. The results are provided in Fig. 11. It shows that the solution, distributed on 4 machines (4 instances) can handle up to 170 users

\section{Figure 11}

Performance of the solution when simulating practical application

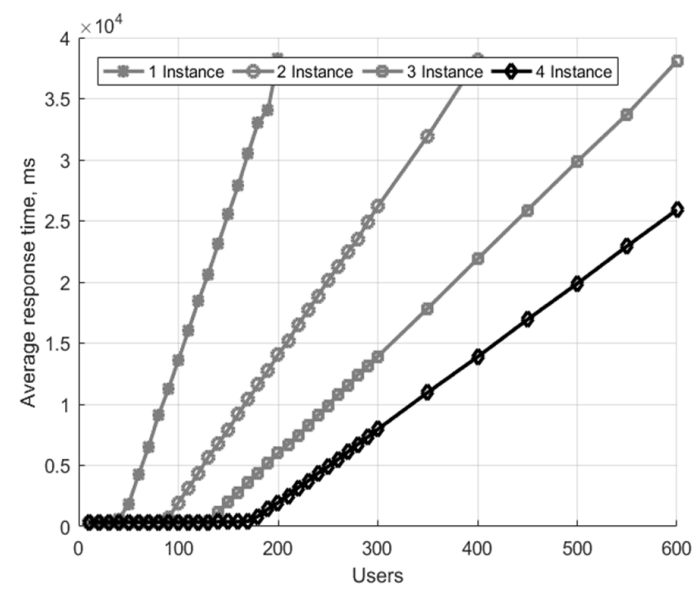

without degrading behaviour. The system degrades linearly with bigger number of users.

\section{Conclusions}

Medical systems are increasingly being implemented as cloud-based services to use the benefits of cloud computing. Our task was to study the effectiveness of cloud-based solution designed for near real-time ECG signal analysis to replace legacy systems. For that purpose, a system, which includes service-oriented architecture solution as well as algorithms for the ECG signal analysis, was created.

The study of the implemented algorithms shows that: - The BEADS algorithm with normalized frequency $f_{c}=0.01$ and asymmetry $r$ from 1 to 6 is the best trend removal method for analysed ECG signal.

- The DWT algorithm was selected for ECG signal noise reduction. The best results were found with Daubechies wavelet 'db11' and they caused just 0.0559 RMSE error.

The study of the cloud-based solution shows that:

- The performance of the proposed cloud-based solution with four dedicated virtual machines allows serving approximately 250 concurrent users for the given use case.

- The efficiency is sufficient for the most use cases, although the improvement on architectural and algorithm levels is needed.

The future works will contain data compression, automated health evaluation and training methodology system using decision making algorithms.

\section{Acknowledgment}

This work was supported by a grant from the Agency for Science, Innovation and Technology (MITA) regarding Eureka project ITEA2 CareWare 13034.

2. Akshay, N., Jonnabhotla, N. A. V., Sadam, N., Yeddanapudi, N. D. ECG Noise Removal and QRS Complex Detection Using UWT. ICEIE, 2010, 2, 438-442. https:// doi.org/10.1109/ICEIE.2010.5559812 
3. AlMahamdy, M. Riley, D. Performance Study of Different Denoising Methods for ECG Signals. The 4th International Conference on Current and Future Trends of Information and Communication Technologies in Healthcare (ICTH-2014), Elsevier, Procedia Computer Science 37, 2014, 325-332. https://doi.org/10.1016/j. procs.2014.08.048

4. Anuradha, B., Veera Reddy, V. C. ANN for Classification of Cardiac Arrhythmias. ARPN Journal of Engineering and Applied Sciences, 2008, 3(3), 1-6.

5. Arvinti, B., Costache, M., Toader, D., Oltean, M., Isar, A. ECG Statistical Denoising in the Wavelet Domain. IEEE, 9th International Symposium on Electronics and Telecommunications (ISETC), 2010, 307-310. https://doi.org/10.1109/ISETC.2010.5679269

6. Babu, S., Chandini, M., Lavanya, P., Ganapathy, K., Vaidehi, V. Cloud-Enabled Remote Health Monitoring System. International Conference on Recent Trends in Information Technology (ICRTIT), 2013, 702-707. https://doi.org/10.1109/ICRTIT.2013.6844286

7. Bui, N., Zorzi, M. Health Care Applications: A Solution Based on the Internet of Things. Proceedings of the 4th International Symposium on Applied Sciences in Biomedical and Communication Technology, (ISABEL'11), New York, NY, USA: ACM, 2011, 131:1-131:5. https://doi.org/10.1145/2093698.2093829

8. Chen, S.W., Chen, Y. H. Hardware Design and Implementation of Wavelet De-Noising Procedure for Medical Signal Preprocessing. Sensors, 2015, 15, 2639626414. https://doi.org/10.3390/s151026396

9. Clifford, G. D., Azuaje, F., McSharry, P. Advanced Methods and Tools for ECG Data Analysis. Artech House Publishers, Norwood, 2006.

10. Elbuni, A., Kanoun, S., Elbuni, M., Ali, N. ECG Parameter Extraction Algorithm Using (DWTAE) Algorithm. International Conference on Computer Technology and Development, 2009, 57-62.

11. Elgendi, M., Eskofier, B., Abbott, D. Fast T Wave Detection Calibrated by Clinical Knowledge with Annotation of P and T Waves. Sensors, 2015, 15(7), 1769317714. https://doi.org/10.3390/s150717693

12. Gao, D. Madden, M. Bayesian ANN Classifier for ECG Arrhythmias Diagnostic System. Proceedings of IEEE International Joint Conference on Neural Network, 2003, 2454-2459.
13. Garg, G., Singh, V., Gupta, J. R. P., Mittal, A. P. Optimal Algorithm for ECG Denoising Using Discrete Wavelet Transforms. 2010 IEEE International Conference on Computational Intelligence and Computing Research (ICCIC), 2010. https://doi.org/10.1109/ICCIC.2010.5705839

14. German-Sallo, Z., Lutean, C. Wavelet Packet Transform Based ECG Signal Filtering Implemented in Reconfigurable Hardware Structure. Scientific Bulletin of the «Petru Maior» Universtity of Tirgu Mures, 2014, 11(1), 42-45.

15. Hoffmann, K., Wiemeyer, J., Hardy, S., Göbel, S. Personalized Adaptive Control of Training Load in Exergames from a Sport-Scientific Perspective. In: Göbel S., Wiemeyer J. (Eds.) Games for Training, Education, Health and Sports. GameDays 2014, Lecture Notes in Computer Science, 8395, 129-140. https://doi. org/10.1007/978-3-319-05972-3_14

16. Hölzl, M., Gabor, T. Continuous Collaboration: A Case Study on the Development of an Adaptive Cyber-Physical System. IEEE/ACM 1st International Workshop on Software Engineering for Smart Cyber-Physical Systems (SEsCPS), 2015, 19-25.

17. Jagtap, S. K., Uplane, M. D. The Impact of Digital Filtering to ECG Analysis: Butterworth Filter Application. International Conference on Communication, Information \& Computing Technology (ICCICT), 1920 Oct., 2012.

18. James, D. A., Petrone, N. Sensors and Wearable Technologies in Sport: Technologies, Trends. and Approaches for Implementation SpringerBriefs in Applied Sciences and Technology, 2016. https://doi. org/10.1007/978-981-10-0992-1

19. Jokic, S., Krco, S., Delic, V., Sakac, D., Jokic, I., Lukic, Z. An Efficient ECG Modeling for Heartbeat Classification. 10th Symposium on Neural Network Applications in Electrical Engineering, 2010, 73-76. https:// doi.org/10.1109/NEUREL.2010.5644105

20. Kadambe, S., Murray, R., Boudreaux-Bartels, G. F. Wavelet Transform-Based QRS Complex Detector. IEEE Transactions on Biomedical Engineering, 1999, 46(7), 838-848. https://doi.org/10.1109/10.771194

21. Karam, M., Khazaal, H. F., Aglan, H., Cole, C. Noise Removal in Speech Processing Using Spectral Subtraction. Journal of Signal and Information Pro- 
cessing, 2014, 5, 32-41. https://doi.org/10.4236/ jsip.2014.52006

22. Kaur, M., Singh, B., Ubhi, J. S., Rani, S. Digital Filteration of ECG Signals for Removal of Baseline Drift. International Conference on Telecommunication Technology and Applications, Singapore, 2011, 5, 105109.

23. Köhler, B.-U., Hennig, C., Orglmeister, R. The Principles of Software QRS Detection. IEEE Engineering in Medicine and Biology, 2002, 42-57.

24. Mehta, S. S., Lingayat, N. S. Detection of P and T Waves in Electrocardiogram. Proceedings of the World Congress on Engineering and Computer Science, 22-24 Oct., 2008.

25. Messaoud, M. B., Khelil, B., Kachouri, A. Analysis and Parameter Extraction of $\mathrm{P}$ Wave Using Correlation Method. The International Arab Journal of Information Technology, 2009, 6(1), 40-46.

26. Ning, X., Selesnick, I. W., Duval, L. Chromatogram Baseline Estimation and Denoising Using Sparsity (BEADS). Chemometrics and Intelligent Laboratory Systems. Polytechnic School of Engineering, 2014, 139, 156-167.

27. Pan, J., Tompkins, W. J. A Real-Time QRS Detection Algorithm. IEEE Transactions on Biomedical Engineering, BME-32, 1985, 3, 230-236.

28. Principe, J. C., Euliano V., Lefebvre W. C. Neural and Adaptive Systems: Fundamentals Through Simulations. John Wiley \& Sons, Inc., 2000.

29. Qardiocore Wearable ECG Unlike Any Other. https:// www.getqardio.com/qardiocore-wearable-ecg-ekg-monitor-iphone/

30. Qiu, P., Ray Liu, K. J. A Robust Method for QRS Detection Based on Modified P-Spectrum. IEEE ICASSP, 2008, 501-504. https://doi.org/10.1109/ ICASSP.2008.4517656

31. Ray, P. Home Health Hub Internet of Things (H3iot): An Architectural Framework for Monitoring Health of Elderly People. International Conference on Science Engineering and Management Research (ICSEMR), 2014, 1-3. https://doi.org/10.1109/ ICSEMR.2014.7043542

32. Ranjeet, K., Kumar, A., Pandey, R. K. ECG Signal Compression Using Different Techniques. Advances in Computing, Communication and Control, CCIS 125, 2011, 231-241.

33. Rolim, C., Koch, F., Westphall, C., Werner, J., Fracalossi, A., Salvador, G. A Cloud Computing Solution for Patient's Data Collection in Health Care Institutions. Second International Conference on eHealth, Telemedicine, and Social Medicine, ETELEMED'10, 2010, 95-99. https://doi.org/10.1109/eTELEMED.2010.19

34. Roshan, J. M., Rajendra, A., Hojjat, A. Current Methods in Electrocardiogram Characterization. Computers in Biology and Medicine, 2014, 48, 133-149. https:// doi.org/10.1016/j.compbiomed.2014.02.012

35. Selesnick, I. W., Graber, H. L., Pfeil, D. S., Barbour, R. L. Simultaneous Low-Pass Filtering and Total Variation Denoising. IEEE Transactions on Signal Processing, 2014, 62(5), 1109-1124. https://doi.org/10.1109/ TSP.2014.2298836

36. Tarvainen, M., Ranta-aho, P.O., Karjalainen, P. A. An advanced detrending method with application to HRV analysis. IEEE Tram. Biomed. Eng. vol. 49, pp. 172-175, 2002. https://doi.org/10.1109/10.979357

37. Thakor, N. V., Zhu, Y.-S. Applications of Adaptive Filtering to ECG Analysis: Noise Cancellation and Arrhythmia Detection. IEEE Transactions on Biomedical Engineering, 1991, 38(8), 785-794. https://doi.org/10.1109/10.83591

38. Xiao, T., Fan, W. Modeling and Simulation Framework for Cyber Physical Systems. In: Kim, J.-H., Lee, K., Tanaka, S., Park, S.-H. (Eds.), Advanced Methods, Techniques, and Applications in Modeling and Simulation. Proceedings in Information and Communications Technology, 4, Springer, Tokyo, 2012, 105-115. https://doi.org/10.1007/978-4-431-54216-2_13 


\section{Summary / Santrauka}

This paper introduces a distributed service-oriented system, which is developed to provide ECG (electrocardiogram) monitoring, analysis and storage services. The Service-Oriented Architecture system design is introduced forECGsignaltransmission and processing. Theimplementation of cloud-based web-services and overallsystem architecture is described. The presented system includes a T-shirt with five electrodes intended for the acquisition of the signal. The ECG data for the experiment were recorded while the participant was moving. The signal replicates real conditions and the ECG data contain different high and low frequency noise. Therefore, this paper includes analysis of data filtering methods, model selection and ECG parameter calculation algorithms. The DWT algorithm was selected for the high frequency noise reduction and the BEADS method was used for trend removal. It was experimentally identified that these algorithms are effective and can be used in the system under development. The tests covering overall system were performed on an Amazon cloud computing infrastructure. The results are presented together with a discussion of various constraints of service-oriented performance.

Straipsnyje pristatoma saityno paslaugų sistema, skirta EKG (elektrokardiogramos) signalo stebėsenai, analizei ir saugojimui. Pateikiama ir aprašoma ị saityno paslaugas orientuota sistemos architektūra, realizuojanti EKG signalo perdavimą ir apdorojimą debesų kompiuterijos priemonèmis. Signalo registravimui naudojami išmanūs marškinèliai su penkiais integruotais elektrodais. EKG duomenys buvo įrašomi treniruotès metu, kai eksperimento dalyvis atlikinèjo įvairius fizinius pratimus. Tokiu būdu gautas signalas yra panašus ị realiomis sąlygomis išgaunamą signalą, kuris turi aukšto ir žemo dažnio triukšmą. Straipsnyje aprašomi signalo filtravimo algoritmai, atliekama jų analizè ir aprašomi EKG parametrų skaičiavimo algoritmai. Aukšto dažnio triukšmo sumažinimui parinktas DWT algoritmas, o žemo dažnio triukšmo pašalinimui - BEADS metodas. Eksperimento metu buvo nustatyta, kad šie algoritmai yra efektyvūs ir tinkami kuriamai sistemai. Buvo atlikti našumo testai sistemai, įdiegtai „Amazon cloud“ debesų kompiuterijos infrastruktūroje. Straipsnyje pristatomi rezultatai ir diskusija, susijusi su tokios realizacijos sistemos našumu. 